\title{
PENGETAHUAN DAN MOTIVASI TIM KAMAR BEDAH DENGAN KEPATUHAN PENGISIAN SURGICAL SAFETY CHECKLIST
}

\author{
Setyajid Joko Muara1, Mustiah Yulistiani $^{2}$ \\ ${ }^{2}$ Fakultas Ilmu Kesehatan Program Studi Sarjana Keperawatan \\ Universitas Muhammadiyah Purwokerto 2020 \\ Dusun II, Sokaraja Kulon, Kec. Sokaraja, Kabupaten Banyumas, Jawa Tengah 53181 \\ sjokomuara@gmail.com
}

\begin{abstract}
Abstrak
Patient safety merupakan salah satu upaya dalam memperbaiki mutu pelayanan dalam pemberian asuhan keperawatan. Patient safety didalam kamar bedah dilaksanakan dengan menggunakan Surgical Safety Checklist. Tujuan penelitian ini adalah mengidentifikasi hubungan pengetahuan dan motivasi tim kamar bedah dengan kepatuhan pengisian surgical safety checklist Di Instalasi Bedah Sentral RSUD Banyumas. Metode penelitian survey analitik dengan desain cross sectional dengan point time approach. Populasi semua tim operasi di ruang Instalasi Bedah Sentral RSUD Banyumas sebanyak 45 orang dengan sampel dokter penanggung jawab 15, dokter anestesi 3, perawat instrument 16, perawat anestesi sebanyak 11. Instrumen penelitian pengetahuan, motivasi adalah kuesioner dan surgical safety checklist. Uji statistik yang digunakan spearman rank. Hasil penelitian didapatkan tim kamar operasi RSUD Banyumas memiliki tingkat pengetahuan cukup sebanyak 46,7\%, motivasi tinggi sebanyak $66,7 \%$ dan mayoritas patuh dalam pengisian surgical safety checklist sebanyak 73,3\%. Terdapat hubungan tingkat pengetahuan dengan kepatuhan tim kamar operasi nilai $\mathrm{p}=0,039$ sedangkan tingkat motivasi dengan kepatuhan tim kamar operasi nilai $\mathrm{p}=0.032$. Hasil penelitian menunjukan terdapat hubungan tingkat motivasi dengan kepatuhan tim kamar operasi di Instalasi Bedah Sentral RSUD Banyumas.
\end{abstract}

Kata kunci: pengetahuan, motivasi, kepatuhan, Daftar Periksa Keselamatan Bedah

\begin{abstract}
Patient safety is one of the efforts in improving the quality of service in the provision of nursing care. Patient safety in the surgical room is carried out using the Surgical Safety Checklist. The goal of this study was to identify the knowledge and motivation relationship of the surgical room team with surgical safety filling compliance with checklist in Central Surgical Installation RSUD Banyumas. Analytical survey research method with cross sectional design with point time approach. The population of all the operating teams in the Central Surgical Installation room of Banyumas Hospital is 45 people with a sample of doctors in charge of 15, anesthesiologists 3 , instrument nurses 16, anaesthetization nurses as many as 11. Knowledge research instruments, motivation is a questionnaire and surgical safety checklist. Statistical tests used spearman rank. The results of the study obtained by the banyumas hospital operating room team had a sufficient level of knowledge as much as $46.7 \%$, high motivation as much as $66.7 \%$ and the majority obeyed in filling surgical safety checklist as much as $73.3 \%$. There is a knowledge level relationship with the compliance of the operating room team $p$ value $=0.039$ while the motivation level with the compliance of the operating room team $p$ value $=0.032$. Research shows that there is a relationship of motivation levels with the compliance of the operating room team at the Central Surgical Installation of Banyumas Hospital.
\end{abstract}

Keywords: knowledge, motivation, compliance, surgical safety checklist

Corresponding author:

Setyadid Joko Muara

sjokomuara@gmail.com 


\section{PENDAHULUAN}

Rumah Sakit adalah instansi pemberi pelayanan kesehatan. Pelayanan kesehatan yang ada di Rumah Sakit salah satunya yaitu Pelayanan Instalasi Bedah Sentral (IBS) (Trisna $\mathrm{E}$, 2018). IBS merupakan tempat pelayanan kesehatan untuk menangani pasien yang akan dilakukan tindakan pembedahan. Setiap tahunnya ada 100 juta lebih orang untuk dilakukan tindakan operasi (World Health Organization, 2012)

IBS merupakan salah satu ruangan pelayanan pembedahan dengan memiliki resiko serta angka kejadian kecelakaan, apabila dalam pelaksanaannya tidak mengutamakan keselamatan pasien, kesiapan pasien, dan prosedur (Suharyanto, 2012). Petugas IBS per tim memiliki peran yang berbeda-beda pada saat menjalankan pekerjaanya, namun yang perlu diperhatikan adalah keselamatan pasien (patient safety) (Mamesah dan Nursalam, 2018).

Patient safety adalah tindakan dalam menjaga mutu pelayanan kesehatan pada saat memberikan asuhan keperawatan (Cahyono, 2008). Patient safety didalam kamar bedah dilaksanakan dengan menggunakan Surgical Safety Checklist. Surgical Safety Checklist adalah sebuah daftar periksa untuk memberikan pembedahan yang aman dan berkualitas pada pasien. Safety dan Complience (2012) menyatakan bahwa Surgical Safety Checklist adalah instrumen komunikasi, untuk menjalankan kerjasama antar tim dalam mencapai keselamatan pasien diruang operasi dalam upaya peningkatkan kualitas pelayanan kesehatan. Selain itu, instrumen ini juga digunakan untuk menurunkan kematian dan komplikasi akibat pembedahan serta terjadinya kejadian tidak di inginkan (Elrifda S, 2011).

Berdasarkan hasil penatalaksanaan
WHO terhadap penerapan Surgical Safety Checklist di delapan rumah sakit diperoleh ada penurunan kejadian komplikasi terhadap operasi darurat sebanyak $63,6 \%$, kematian sebanyak $3,7 \%$ menjadi $1,4 \%$, (ILO) ada $11,2 \%$ turun $6,6 \%$ dan kehilangan darah > $500 \mathrm{ml}$ turun ada $20,2 \%$ turun $13,2 \%$ (Weiser GT et al, 2008).

Berdasarkan data di kamar bedah RSUD Banyumas tahun 2018, pasien yang akan menjalani operasi sudah dilengkapi dengan formulir Surgical Safety Checklist, tetapi dalam pelaksanaannya belum sempurna.

Tujuan dari penelitian untuk mengetahui hubungan tingkat pengetahuan dengan kepatuhan pengisian surgical safety checklist dan hubungan motivasi dengan kepatuhan pengisian surgical safety checklist oleh tim kamar operasi RSUD Banyumas

\section{METODE PENELITIAN}

Peneliti menggunakan desain survey analitik dengan cross sectional dan pendekatan point time approach. Populasi dalam penelitian ini adalah semua tim operasi di ruang Instalasi Bedah Sentral RSUD Banyumas dengan jumlah 45 orang yang terdiri dari dokter penanggung jawab 15, dokter anestesi 3, perawat instrumen 16, perawat anestesi sebanyak 11. Sampel seluruh tim kamar bedah yang terlibat dalam proses pembedahan. Penelitian dilakukan di Instalasi Bedah Sentral RSUD Banyumas pada tanggal 28 November - 28 Desember 2019. Instrumen penelitian pengetahuan, motivasi adalah kuesioner dan surgical safety checklist. Uji statistik yang digunakan spearman rank. 


\section{HASIL}

Tabel 1 Distribusi Frekuensi Karakteristik Tim Kamar Operasi di Instalasi Bedah Sentral RSUD Banyumas

\begin{tabular}{llll}
\hline No & Karakteristik & F & $\%$ \\
\hline 1 & Usia & & \\
& Dewasa awal & 2 & 4,4 \\
& Dewasa akhir & 43 & 95,6 \\
\cline { 2 - 4 } & Jumlah & 45 & 100 \\
\hline 2 & Pendidikan & & \\
& Spesialis & 17 & 37,8 \\
& Sarjana & 2 & 4,4 \\
& Diploma & 26 & 57,8 \\
\cline { 2 - 4 } & Jumlah & 45 & 100 \\
\hline 3 & Jenis kelamin & & \\
& Laki-laki & 38 & 84,4 \\
& Perempuan & 7 & 15,6 \\
\cline { 2 - 4 } & Jumlah & 45 & 100,0 \\
\hline 4 & Lama Kerja & & \\
& < 10 tahun & 20 & 44,4 \\
& $\geq 10$ tahun & 25 & 55,6 \\
\hline & Jumlah & 45 & 100,0 \\
\hline
\end{tabular}

Tabel 1 menunjukkan bahwa sebagian tim kamar operasi di Instalasi Bedah Sentral RSUD Banyumas berusia dewasa akhir sebanyak $95,6 \%$ dengan jenis kelamin laki-laki sebanyak $84,4 \%$. Tingkat pendidikan sebagian besar diploma sebanyak 57,8\% dengan lama kerja Sebagian besar lebih dari 10 tahun sebanyak $55,6 \%$.

Tabel 2 Distribusi Frekuensi Tingkat Pengetahuan Tim Kamar Operasi di Instalasi Bedah Sentral RSUD Banyumas

\begin{tabular}{llll}
\hline No & Tingkat Pengetahuan & Frekuensi & $\%$ \\
\hline 1. & Baik & 11 & 24,4 \\
2. & Cukup & 21 & 46,7 \\
3. & Kurang & 13 & 28,9 \\
\hline & Total & 45 & 100,0 \\
\hline
\end{tabular}

Tabel 2 menunjukkan bahwa sebagian besar tim kamar operasi di Instalasi Bedah Sentral RSUD Banyumas memiliki tingkat pengetahuan cukup sebanyak 46,7\%.

Tabel 3 Distribusi Frekuensi Motivasi Tim Kamar Operasi di Instalasi Bedah Sentral RSUD Banyumas

\begin{tabular}{llcc}
\hline No & Tingkat Motivasi & Frekuensi & $\%$ \\
\hline 1. & Tinggi Motivasi & 30 & 66,7 \\
2. & Kurang Motivasi & 15 & 33,3 \\
\hline & Total & 45 & 100,0 \\
\hline
\end{tabular}

Tabel 3 menunjukkan bahwa sebagian besar tim kamar operasi di Instalasi Bedah Sentral RSUD Banyumas memiliki motivasi tinggi sebanyak $66,7 \%$. 
Tabel 4 Distribusi Frekuensi Tingkat Kepatuhan dalam Pengisian Surgical Safety Checklist Tim Kamar Operasi di Instalasi Bedah Sentral RSUD Banyumas

\begin{tabular}{llll}
\hline No & $\begin{array}{l}\text { Tingkat } \\
\text { Kepatuhan }\end{array}$ & Frekuensi & $\%$ \\
\hline 1. & Patuh & 33 & 73,3 \\
2. & Tidak patuh & 12 & 26,7 \\
\hline & Total & 45 & 100,0 \\
\hline
\end{tabular}

Tabel 4 menunjukkan bahwa mayoritas tim kamar operasi Tim Kamar Operasi di Instalasi Bedah Sentral RSUD Banyumas patuh dalam pengisian surgical safety checklist sebanyak 73,3\%.

Tabel 5 Hubungan Tingkat Pengetahuan Dengan Kepatuhan Tim Kamar Operasi Di Instalasi Bedah Sentral RSUD Banyumas

\begin{tabular}{lllllll}
\hline \multirow{2}{*}{ Pengetahuan } & \multicolumn{5}{c}{ Kepatuhan } \\
\cline { 2 - 7 } & \multicolumn{2}{c}{ Patuh } & \multicolumn{2}{c}{ Tidak patuh } & \multicolumn{2}{c}{ Total } \\
\cline { 2 - 7 } & f & $\%$ & $\mathrm{f}$ & $\%$ & $\mathrm{f}$ & $\%$ \\
\hline Baik & 10 & 90,0 & 1 & 9,1 & 11 & 100 \\
Cukup & 16 & 76,2 & 5 & 23,8 & 21 & 100 \\
Kurang & 7 & 53,8 & 6 & 46,2 & 13 & 100 \\
\hline Total & 33 & 73,3 & 12 & 26,7 & 45 & 100 \\
\hline \multicolumn{6}{l}{ Pv $0.039 ;$ Rho : 0,309} \\
\hline
\end{tabular}

Tabel 5 menunjukkan bahwa tingkat pengetahuan baik dengan kepatuhan dalam pengisian surgical safety checklist sebanyak $90 \%$ dengan nilai $\mathrm{p}=0,039$ dan nilai $\mathrm{r}=0,309$. Hal ini menunjukkan bahwa terdapat hubungan antara tingkat pengetahuan dengan kepatuhan pengisian surgical safety checklist dengan kekuatan hubungan lemah.

Tabel 6 Hubungan Tingkat Motivasi Dengan Kepatuhan Tim Kamar Operasi di Instalasi Bedah Sentral RSUD Banyumas

\begin{tabular}{|c|c|c|c|c|c|c|}
\hline \multirow{3}{*}{ Tingkat Motivasi } & \multicolumn{6}{|c|}{ Kepatuhan } \\
\hline & \multicolumn{2}{|c|}{ Patuh } & \multicolumn{2}{|c|}{ Tidak patuh } & \multicolumn{2}{|c|}{ Total } \\
\hline & $\mathrm{f}$ & $\%$ & $\mathrm{f}$ & $\%$ & $\mathrm{f}$ & $\%$ \\
\hline Tinggi & 19 & 63,3 & 11 & 36,7 & 30 & 100 \\
\hline Kurang & 14 & 93,3 & 1 & 6,7 & 15 & 100 \\
\hline Total & 33 & 73,3 & 12 & 26,7 & 45 & 100 \\
\hline \multicolumn{7}{|c|}{ Pv $0.032 ;$ Rho : 0,320} \\
\hline
\end{tabular}

Tabel 6 menunjukkan bahwa tingkat motivasi tinggi dengan kepatuhan dalam pengisian surgical safety checklist sebanyak $63,3 \%$ dengan nilai $\mathrm{p}=0,032$ dan nilai $\mathrm{r}=0,320$. Hal ini menunjukkan bahwa terdapat hubungan antara tingkat motivasi dengan kepatuhan pengisian surgical safety checklist dengan kekuatan hubungan lemah.

\section{PEMBAHASAN}

Berdasarkan tabel 1 diketahui bahwa tim kamar operasi di Instalasi Bedah Sentral RSUD Banyumas sebagian besar berusia dewasa akhir $(95,6 \%)$, berpendidikan diploma $(57,8 \%)$ berjenis kelamin laki-laki $(84,4 \%)$ dan bekerja $\geq 10$ tahun.

Berbeda dengan penelitian Selano dkk. (2013) yang menjelaskan bahwa sebagian besar responden berusia 31-40 tahun (43,48\%). Secara umum, umur memiliki peran penting dalam menentukan tingkat kedewasaan dan rasa tanggung jawab seseorang dalam melakukan aktivitas maupun pekerjaan. Seiring bertambahnya usia, maka seseorang semakin mampu mengontrol emosi, bijaksana, tanggung jawab dalam bekerja dan berpikir rasional (Arifianto, 2017).

Pendidikan akan mempengaruhi pengetahuan (Notoatmodjo, 2012). Tingkat Pendidikan yang tinggi akan memudahkan seseorang untuk menerima informasi sehingga pengetahuan akan bertambah.

Seorang laki-laki memiliki sifat agresif jika dibandingkan perempuan. Namun, jika 
wanita wanita yang ingin menjadi sukses serta memiliki beban tanggung jawab di dalam rumah akan menjadikan seorang wanita lebih agresif jika dibandingkan laki-laki (Arifianto, 2017).

Sejalan dengan Mamesh dan Nursalam (2018) dalam penelitiannya menyebutkan bahwa sebagian besar responden bekerja $>14$ tahun $(58,3 \%)$. Menurut teori yang ada bahwa semakin lama seseorang bekerja maka semakin baik tingkat produktifitas yang dihasilkan.

Dalam meningkatkan kepatuhan pelaksanaan surgical safety checlist perlu ada kematangan usia pendidikan masa kerja yang cukup lama di imbangi dengan kekuatan fisik yang kuat sehingga akan menghasilkan pekerjaan yang lebih baik

Berdasarkan hasil penelitian pada tabel 2 diketahui bahwa sebagian besar responden memiliki tingkat pengetahuan cukup $(46,7 \%)$ dan sebagian kecil memiliki tingkat pengetahuan baik $(24,4 \%)$. Pengetahuan yang kurang tentang SSC akan menyebabkan pemahaman yang kurang tentang SSC sehingga dalam pengisian SSC akan dianggap oleh perawat suatu beban,

Tabel 3 dapat diketahui bahwa sebagian besar responden memiliki tingkat motivasi tinggi $(66,7 \%)$. Semakin tinggi motivasi seseorang maka akan mempengaruhi tingkat kepatuhan dalam pengisian surgical safety cheklist yang baik (Nursalam, 2014) Dorongan yang sangat kuat untuk melaksanakan surgical safety cheklist akan dapat membantu meningkatkan kinerja diri sendiri dan tim sehingga akan mendapatkan hasil yang maksimal

Berdasarkan tabel 4 dapat diketahui bahwa sebagian besar responden patuh $(73,3 \%)$. Sejalan dengan penelitian Trisna (2016) yang menjelaskan bahwa sebagian besar Tim Bedah patuh terhadap Surgical Patient Safety Pada Pasien Operasi Bedah (60\%).kepatuhan yang stabil berjalan terus menerus menghasilkan perilaku yang akan membawa pada sebuah keberhasilan dalam pelaksanaan SSC.

Tabel 5 dapat diketahui bahwa analisis data menggunakan uji spearman rank diperoleh p $0.039<\alpha$, maka Ho ditolak dan Ha diterima, yang artinya terdapat hubungan tingkat pengetahuan dengan kepatuhan tim kamar operasi di Instalasi Bedah Sentral RSUD Banyumas. Uji keeratan diperoleh nilai 0,309 sehingga dapat diinterpretasikan bahwa semakin tinggi tingkat pengetahuan maka semakin tinggi kepatuhan responden.

Berdasarkan tabel 6 dapat diketahui bahwa analisis data menggunakan uji spearman rank diperoleh $p 0.032<\alpha$, maka Ho ditolak dan Ha diterima, yang artinya terdapat hubungan tingkat motivasi dengan kepatuhan tim kamar operasi di Instalasi Bedah Sentral RSUD Banyumas. Uji keeratan diperoleh nilai 0,320 sehingga dapat diinterpretasikan bahwa semakin tinggi tingkat motivasi maka semakin tinggi kepatuhan responden.

\section{KESIMPULAN}

Umur rata-rata tim kamar operasi di Instalasi Bedah Sentral RSUD Banyumas 46,04 tahun sebagian besar berjenis kelamin laki-laki dan bekerja $\geq 10$ tahun. Tingkat pengetahuan cukup dan tingkat motivasi tinggi, serta mayoritas patuh dalam pengisian surgical safety checklist.Terdapat hubungan tingkat pengetahuan dengan kepatuhan tim kamar operasi. Terdapat hubungan tingkat motivasi dengan kepatuhan tim kamar operasi.

\section{DAFTAR PUSTAKA}

Arifianto. (2017). Kepatuhan Perawat dalam Menerapkan Sasaran Keselamatan Pasien pada Pengurangan Risiko Infeksi dengan Penggunaan Alat Pelindung Diri di RS. Roemani Muhammadiyah Semarang. Tesis. Universitas Diponegoro.

Cahyono. (2008). membangun budaya keselamatan pasien dalam praktek kedokteran. Jogjakarta: Kanasius.

Elrifda S. (2011). budaya patient safety dan karakteristik kesalahan pelayanan: implikasi kebijakan di salah satu rumah sakit di kota Jambi. 6(2).

Mamesah, dan Nursalam. (2018). hubungan motivasi tim bedahdengankepatuhan penggunaan surgical safety checklist di kamar bedah RSU GMIM Bathesda Tomoho. 8(1).

Notoatmodjo S. (2012). Promosi kesehatan dan ilmu perilaku. Jakarta: Rineka Cipta.

Nursalam. (2014). Management keperawatan Aplikasi Dalam Praktik Keperawatan Profesional. Jakarta: Salemba Medika.

Selano, M. K., Kurniawan, Y. H., \& Sambodo, P. (2019). Hubungan Lama Kerja Perawat 
Dengan Kepatuhan Pengisian Surgical Safety Checklist di Instalasi Bedah Sentral. Jurnal Kepemimpinan dan Manajemen Keperawatan, 2(1), 16-22.

Suharyanto. (2012). Analisis Faktor-Faktor Yang Berkontribusi Terhadap Patient Safety Di Kamar Operasi RS Bintaro. 235.

Trisna E. (2018). Hubungan persepsi tim bedah dengan kepatuhan penerapan surgical patient safety pada pasien operasi bedah rumah sakit umum daerah mayjend HM Ryacudu. Jurnal Kesehatan. 7(2), 341.

Weiser GT et al. (2008). An Estimation Of The Global Volume Of Surgery: A Modelling Strategy Based On Available Data. 